\title{
Vivencias, prácticas y concepciones urbanas en el barrio del Puerto de Tarragona
}

\author{
Miguel González \\ Doctorado en Antropologia i Comunicació, \\ Universitat Rovira i Virgili \\ mgmfs84@gmail.com
}

Resumen: Con base etnográfica, el presente artículo aborda la transformación social y espacial que el Barrio del Puerto de Tarragona ha vivido en las últimas décadas y el resultado con el que se enfrenta al futuro. Parte de un análisis de corte lefebvriano, pues atiende el plano vecinal cotidiano, el plano de la práctica consciente del espacio y el plano proyectual en sentido político y urbanístico. La realidad de la unidad de observación ha llevado al análisis de fenómenos como la decadencia urbanística, la gentrificación, la xenofobia y la construcción de identidades. El caso refleja los conflictos de los procesos globales en lo particular de un barrio donde los agentes urbanos chocan y confluyen ante la pregunta de qué fueron, qué son y qué quieren ser.

Palabras clave: barrios portuarios; ciudadanía; urbanismo; waterfront; gentrificación

Abstract: The present article takes an ethnographic approach to the social and spatial transformation experienced by the port neighbourhood in Tarragona during recent decades and the challenges that it faces the future. The article begins with a Lefebvrian analysis of everyday life in the neighbourhood, the conscious practice of space and the political and urbanistic project. The nature of the object of study has led to an analysis of phenomena such as urban decay, gentrification, xenophobia and identity construction. The case study reflects conflicts in global processes at the local level of a neighbourhood in which the people wrestle with the questions of who they were, who they are and who they want to be.

Key words; port neighbourhoods; citizenship; urbanism; waterfront; gentrification. 
"Es el espacio y por el espacio donde se produce la reproducción de las relaciones de producción capitalista. El espacio deviene cada vez más un espacio instrumental" (Lefebvre, 1974, en 2013: 223). Esta instrumentalidad pone las partes de las ciudades mejor emplazadas en una situación de centralidad política y económica. Como sucede con los centros históricos de las ciudades, los frentes marítimos y los barrios portuarios son hoy lugares con la capacidad de transformarse en símbolos de contemporaneidad y adecuación de las ciudades al capitalismo vigente, en receptores potenciales de hitos arquitectónicos (Moix, 2010) y funciones relevantes que resumen en una estampa el buen hacer.

Las diversas posiciones de los actores sociales hacen que en mayor o menor medida los barrios sean vividos y observados como lo que son y sobre lo que podrían ser entrando muchas veces en conflictos. La relación, según Lefebvre (1974: 42-49), es dialéctica, y las formas de aproximación al espacio las divide en tres: el espacio vivido, el espacio practicado y el espacio concebido.

El espacio vivido o percibido por los sentidos, de donde parte el apego al paisaje, es la práctica espacial en relación con la experiencia sensorial primera, de donde derivan las posteriores prácticas y representaciones sobre la ciudad. Fue preciso por ello abordar la cuestión del paisaje (incluyendo el paisaje humano) y las sensaciones comprendiendo que no es algo que exista de por sí sino en relación social, es decir, mediado a través de la experiencia y con el condicionante de la identidad (Lynch, 1985; Nogué, 2007).

El espacio practicado o el espacio de la representación es donde confluyen con mayor o menor grado de interacción entre habitantes y usuarios. Se trata del espacio donde se ejerce la sumisión cotidiana al orden del poder a través de las representaciones hegemónicas. Pero también es el espacio de la subalternidad, es decir, el espacio donde se materializan las resistencias a los órdenes. En torno a la transformación de la ciudad, hemos visto que es el espacio público (físico y comunicativo) donde se desarrollan las acciones de la sociedad civil. Aquí lidian las partes en las defensas de sus modelos, es donde las ideologías chocan a través de mayorías silenciosas y resistencias proactivas y/o reactivas. Es el punto de partida de los "estallidos" o "escapes" (Harvey, 2013), es decir, de las presiones desde abajo para transformar la ciudad.

La representación del espacio o el espacio concebido es la imagen ideada por el poder político y técnico para adaptarse a las lógicas del capital actual. Es un imaginario cargado de ideología que requiere de la formalización (a veces ca- 
muflaje) a través del discurso científico de urbanistas, economistas, diseñadores $\mathrm{u}$ otros profesionales considerados pertinentes, de modo que poder público y conocimiento técnico se transforman en numerosas ocasiones en procuradores de la generación de plusvalías. Según Neil Smith, quedan sepultados bajo el concepto «renovación urbana» procesos de gentrificación que suelen esconder operaciones especulativas de fondo que benefician a los especuladores por encima de la vecindad (Smith, 2009: 77 y ss.; Delgado, 2007a y 2007b), que vive procesos de expulsión o empobrecimiento.

La teoría lefebvriana ha condicionado el método de aproximación a la realidad del barri del Port en el contexto de mi tesis doctoral sobre modelos urbanos en ciudades costeras intermedias en el auge y caída de la burbuja inmobiliaria. El trabajo se basa en un conjunto de entrevistas y observaciones realizadas durante los años 2014 y 2015 que buscan comprender las interrelaciones de las diversas escenas sociales del barrio con el mismo, la representación de sus actores sobre este y la concepción de técnicos y políticos. El análisis de discursos sumado a la documentación histórica, estadística y hemerográfica ha hecho posible extraer un retrato social ligado al devenir espacial y poder utilizarlo para extraer tendencias comparándolo con diversas casuísticas.

Aclaro aquí que, aunque las referencias teóricas que se exponen en el texto son de utilidad, es peligroso importar modelos teóricos y prácticos del urbanismo basados en ciudades de mayor centralidad como las que han servido de paradigma para la teorización y práctica urbanística. De hecho, este texto expone cómo se imagina un núcleo periférico e intermedio a sí mismo bajo la óptica urbanística de las ciudades modelo pero que no llegan a encajar con la realidad local. Es la historia de un quiero y no puedo en la segunda década del siglo XXI.

\section{El espacio vivido: paisaje y memoria del Barri del Port. Una primera aproximación}

Tarragona desbordó sus murallas en el siglo xviri para tratar de consolidar un puerto comercial que se desarrollaría sobre la zona del viejo puerto romano, lejos del núcleo principal. Resultó una ciudad con dos cabezas: la Part Alta, la ciudad vieja emplazada sobre una colina, ligada al campo y a la administración; y la Part Baixa, la ciudad portuaria sobre el mar, que es la que aquí abordaremos. Al límite norte de la Part Baixa se establecería la estación de ferrocarril 
en 1856, y las vías, tras el espacio del puerto, impedirían el acceso directo de la ciudad al mar, como sucede actualmente.

Se formarían en la nueva zona de crecimiento dos barrios marítimos muy diferenciados, el barri de la Marina (el primer nombre del actual barri del Port), que es el que aquí nos ocupa, y el Serrallo, un asentamiento de pescadores con cierto carácter liminal al otro lado de las vías que con el tiempo fue convirtiéndose en barrio de la ciudad (González, 2011). A su vez, la Part Baixa puede diferenciarse en lo que fue el viejo barri de La Marina (el barri del Port) y la zona de crecimiento en torno a la Carrer Unió, a la que se suele hacer referencia como Part Baixa, que, como su nombre indica, conectaba la Part Alta con el nuevo núcleo. El barrio portuario, a su vez, se dividía en dos zonas: una parte noble con la plaça dels Carros como principal espacio y acceso a la zona portuaria; y una parte obrera con la plaça dels Infants como eje, donde se emplazaban fábricas como la de Chartreuse o las bodegas De Muller. Si analizamos los edificios más antiguos de ambas partes, contrastan las residencias nobles y la ornamentación de diversos edificios administrativos como la Aduana, la Casa Gasset o la sede de la antigua Junta de Obras del Puerto en el entorno de la plaza de los Carros con las angostas viviendas en bloque y los amplios almacenes repartidos por las calles del Mar, Lleó y Sant Miquel.

No es que fuera un barrio portuario por ser la zona residencial por excelencia de los trabajadores del puerto, aunque también se emplazaban bastantes, sino porque el barrio complementaba las instalaciones portuarias, cuyas actividades requerían de un entramado logístico que superaba los límites del puerto: empresas de transporte, oficinas de cambio, hostales y pensiones, proveedores de recambios, aseguradoras y almacenes se repartían por la zona. Hoy pueden leerse numerosos rótulos en viejas naves degradadas.

El ajetreo portuario hacía que en la plaça dels Carros coincidiesen empresarios y trabajadores portuarios, obreros y desempleados en busca de trabajo, abogados y oficinistas que se entremezclaban con el tránsito de los vecinos y visitantes. Aún hoy algunos informantes exaltan ciertas figuras de la burguesía y la política local que se asentaron en el barrio, como documentaron Escoda y Baiges (2005) y De Ortueta (2006) para mostrar un pasado con mayores reconocimientos que los actuales. Pero los vecinos con mayor capacidad de consumo se fueron marchando a medida que otras nuevas zonas de la ciudad se 
consolidaban, un hecho que ha llevado a que la composición social del barrio hoy tenga una avanzada edad y rentas más bajas que en otros tiempos. Esta realidad explica las menciones al pasado a la hora de ennoblecer el barrio. El carácter portuario es evocado en la sede de su asociación vecinal, cuyas paredes lucen fotografías de sus calles y plazas llenas de vida, viejos talleres de boteros y calafates, así como el muelle colmado de mercancías. El logotipo de la asociación, además, es una grúa de carga.

La actividad visible en la zona es mínima: un par de bares añejos, algunos niños jugando en los columpios de la plaza principal y un par de bancos ocupados por adultos. Los cristales rotos en el suelo son muy habituales y el tránsito de peatones se limita prácticamente a algunas personas que usan el paso a nivel que lleva al otro lado de las vías.

Además, las narraciones sobre la última etapa de gran actividad portuaria que condicionaba al barrio hacen referencia a la ubicación de numerosos burdeles, sobre todo en carrer del Mar, Lleó y Sant Miquel, que los vecinos asocian a la marinería.

Mira que la gente del puerto ha cobrado bien siempre y ha gastado mucho. [...] cuando la Parte Alta empezó a ponerse bien fueron bajando aquí los puticlubs (CS, antiguo vecino y comerciante del barrio).

Sí, en este caso, es lo que decimos, en los años 70-80 pues se pusieron hasta puticlubs [... La zona de toda la vida era la Parte Ata y luego aquí. Ya prácticamente no queda ninguno. [...] Por falta de clientela, por... No lo sé (RP, vecino propietario asociado).

La trayectoria del barrio cambió a finales de los años ochenta cuando la Autoridad Portuaria cedió al Ayuntamiento el viejo Moll de Costa para uso ciudadano y comenzó la tendencia a construir un frente marítimo al estilo del urbanismo del momento, integrado y dotacional, un nuevo espacio central. El proceso se da a la vez que se construyen enormes polígonos industriales que atrajeron actividades antes emplazadas en el barrio, produciendo un acelerado proceso de vaciamiento de actividades. Los casos más significativos por su impacto serían el cese de actividad de la fábrica de Chartreuse en 1989 y el desplazamiento de las bodegas De Muller al término de Reus. Además, se dio otro cambio en las funciones: el uso semiindustrial declarado de la zona hizo 
que, a medida que el automóvil se expandió y el sector portuario se reubicó, muchos de los bajos que antes eran almacenes, tabernas y burdeles pasaran a ser talleres mecánicos.

Otros viejos almacenes y destilerías se fueron quedando vacíos y entrando en un fuerte proceso de degradación. Los propietarios de muchos inmuebles, conscientes del alza que vivía el negocio inmobiliario, prefirieron esperar a la ruina y el derribo para aumentar la edificabilidad. La degradación llevó a muchos vecinos a reubicarse en otros barrios. Así lo explica un antiguo vecino de siempre y actual usuario:

Era un barrio próspero [...] pero las casas eran bajitas, viejas. ¿Quién se va a vivir ahí? La gente busca comodidad y se van comprando pisos en Poniente, San Pedro [...], los almacenes se quedan vacíos, la gente se va, las empresas se van y entra en decadencia [...]. Antes había muchos solares (VP, vecino y usuario).

Vacío de vecinos, repleto de solares y menguadas las actividades, el barrio se convertiría en objetivo de renovación espacial y funcional.

\section{El espacio practicado: el cambio social y funcional}

Como advertimos en el marco epistemológico sobre la renovación urbana, el aterrizaje del capital suele venir de la mano de intervenciones públicas que impulsan la rentabilidad de los inversores privados. Franquesa señala que las ciudades "en la segunda mitad de los años noventa abandonaron el énfasis redistributivo para adoptar un enfoque neoliberal por el cual el principal objetivo de los planes de reforma urbanística debía pasar a ser la creación de oportunidades de plusvalía inmobiliaria” (Franquesa, 2013: 13). Esta lógica se pronunció en nuestro contexto especialmente durante el periodo de burbuja inmobiliaria a partir de los noventa.

Si revisamos los movimientos urbanísticos de este periodo en el barri del Port, reconoceremos una intención de revalorización del espacio, donde el papel público es el del acondicionamiento de entornos atractivos para la generación de plusvalías del sector privado. El principal movimiento fue colocar la resolución de la cuestión de la fachada marítima en el centro de la escena política. Se trataba de una operación basada en la eliminación de las vías del ferrocarril. La renovación haría del barrio un lugar privilegiado para el negocio inmobi- 
liario. La cuestión contaba desde principios de los noventa con un consenso sobre su conveniencia, aunque el alto coste y la complejidad de las relaciones de intereses entre administraciones lo dificultaban pese al momento de expansión económica que vivía todo el Estado.

La complejidad de la operación no implicó que no se activasen otras como la construcción del Port Esportiu (1997) y Marina Port (2003), dos proyectos que se justificaron desde la Autoridad Portuaria y el Ayuntamiento, respecto al barrio, como una llamada a un público exterior. Responde a la tendencia la construcción del Palacio de Congresos (1996), obra que, según muchos vecinos, dio un nuevo aire al barrio y activó la renovación de la zona de la estación de ferrocarril, que cuenta con muchas promociones de viviendas surgidas en paralelo al equipamiento. Además de estos movimientos, se produce la ubicación en el barrio de dependencias públicas no vinculadas directamente con el mar (por ejemplo, el departamento de Territorio y Sostenibilidad del Ministerio de Fomento), la apertura del Arxiu del Port o el Museu del Port.

Todos los bordes de la zona vivieron inversiones importantes que buscaban expandir la renovación a través de la inversión privada. Para ello se aprueban planes como la prolongación de la calle Pere Martell, que se comprende junto al desarrollo de la nueva zona de crecimiento conformada por la avenida Vidal i Barraquer, y se cambian los usos del viejo suelo industrial a residencial posibilitando el desarrollo de un nuevo parque residencial. Eran años de una fuerte expansión económica basada en el sector inmobiliario, aquella que se consideró el segundo milagro español (Franquesa, 2017) mientras estuvo en alza, y burbuja inmobiliaria después de su quiebra (Fernández Durán, 2006).

Todo este proceso de crecimiento implicó la atracción de inmigrantes que en el caso del núcleo urbano de Tarragona no se emplazaron en el intramuros ya que esa zona ya vivía un proceso de elitización (Alonso, 2011), sino en los barrios marítimos, barri del Port y el Serrallo, que contaban con menor centralidad y concentraba un parque de viviendas degradado y barato (Achebak y González, 2015). El barrio, por el contingente de inmigrantes, el precio y la tipología de los locales, concentra fruterías, locales de kebabs, locutorios, bares de comida latina y bazares regidos por inmigrantes que han cambiado su paisaje tradicional.

Se dan también los conflictos por la apropiación del espacio en clave de racismo. Como explican Martín Díaz y Cuberos Gallardo: "Es importante su- 
brayar el hecho de que la población inmigrante en España se concentra generalmente en barrios infradotados, en los que los espacios públicos resultan insuficientes para dar cobijo a las necesidades de sociabilidad de esta población. En estas condiciones, es frecuente que los inmigrantes hagan un uso intensivo de los escasos espacios públicos disponibles" (2012). Algunos informantes usan la palabra invasión para explicar la sensación de desposesión respecto a su barrio. $\mathrm{Al}$ respecto, es especialmente significativa la presencia de la única mezquita no emplazada en polígonos industriales de Tarragona, cuya presencia no ha estado libre de polémicas en un periodo de creciente islamofobia, como veremos.

Pero la bonanza económica no duró lo esperado. La quiebra del sector inmobiliario a nivel estatal implicó que se detuviera la renovación del parque residencial, de modo que, aun con grandes equipamientos e instituciones, acumulaba sectores de escasos recursos económicos residiendo en viejas viviendas que contrastaban con los nuevos vecinos en un espacio poco segregado.

La no finalización del proceso ha producido un choque de ideales entre lo que el barrio era, lo que está siendo y lo que podría ser. Vecinos propietarios de siempre, nuevos vecinos con mayor capacidad adquisitiva y nuevos vecinos transnacionales moran en el barrio con percepciones diversas sobre el resultado de los proyectos vigentes. También numerosas instituciones: centros de culto de diversas confesiones, las sedes de las dos instituciones culturales andaluzas (la Casa de Andalucía y la Asociación Folklórica y Cultural Andaluza) y de otras zonas del Estado (la Casa gallega, la asturiana, etc.), la sede de Esquerra Republicana, los locales de las collas festivas del barrio (la Cucafera y la Colla Gegantera), la cofradía del Buen Amor, diferentes ONG como Formació i Treball, el comedor social (que en realidad está en la Part Baixa, lindando con el barrio) y la sede de la Asociación de Vecinos del Barri del Port, que es la principal asociación vecinal, pero no la única, pues las nuevas promociones de viviendas han constituido asociaciones de propietarios. Como usuarios, debemos sumar los practicantes de los centros de culto, los funcionarios de numerosas instituciones públicas, trabajadores de Aduanas o el Arxiu del Port $y$, sobre todo, muchos jóvenes que frecuentan los locales de ocio nocturno. La interrelación es compleja.

Las primeras protestas vecinales respecto a la forma y función del barrio comenzarían cuando los proyectos elitizadores no respondieron a las expectativas. El principal detonante fueron los problemas derivados de la consolidación 
del barrio como zona de ocio nocturno tanto por la apertura del nuevo puerto deportivo como por la zona de pubs y discotecas, y el emplazamiento dentro del mismo barrio de numerosos locales (ruidos, residuos, peleas, vandalismo, etc.). A ese proyecto se añade el hecho de disponer de numerosas naves y almacenes a precios más asequibles que en otras partes de la ciudad, lo que hizo que comenzasen a abrirse muchos pubs aumentando los problemas derivados del ocio, que saltaron al espacio público comunicativo. Los vecinos intensificaron sus protestas (se dan manifestaciones por el peligro del paso a nivel, carteles contra el ruido, cartas al periódico, etc.) y el barrio comenzó a llenarse de referencias negativas. Empezaría entonces el tema de la inseguridad, primero nocturna y posteriormente cotidiana, a ganar protagonismo.

Tras la dejadez y ante el escenario de conflicto derivado de la inadecuación entre los recientes planes de inversión pública y buena parte de los habitantes y negocios, apareció el discurso higienista. Este discurso se concentraría en los sectores sociales de más visibilidad y menos capacidad de consumo, los inmigrantes, que se señalarían como sector conflictivo.

La visibilidad de los inmigrantes en los primeros años del boom migratorio fue notable en los medios de comunicación. En primer lugar, las sonadas peleas en el Port Esportiu tuvieron protagonistas locales y extranjeros, pero la visibilidad de los extranjeros fue mucho mayor debido a que los propios motivos de las peleas fueron la condición de extranjería, la denegación del acceso por la condición de extranjero, los conflictos entre pandillas, etc. Si atendemos a las noticias de sucesos de esa época veremos que la cuestión de las nacionalidades está especialmente exaltada. Eso ha llevado a que se identifique a los inmigrantes residentes en el barrio con los conflictos que pasaban al otro lado de las vías aunque no quedase demostrada la residencia en este de los mismos.

Los conflictos fueron a menos en una relación directamente proporcional al fracaso de los locales de ocio nocturno vinculados al enorme estigma del port. Esta etapa, con sus conflictos e hitos, vive hoy en el imaginario de los vecinos del barrio y del resto de la ciudad. Tras el asesinato de un vecino de Camp Clar en 2005, el Port Esportiu caía en una decadencia absoluta, y además de acumular significaciones en relación a la criminalidad, se convertía en otro espacio fracasado de la ciudad turística. Desde ese momento la gran mayoría de los pubs había cerrado y el ocio nocturno se concentró en el mismo entramado del barrio con las consecuentes molestias hacia los vecinos. El ruido y el vandalis- 
mo ligado al ocio nocturno llevaron a optar por una mayor vigilancia para la seguridad con la instalación de cámaras de videovigilancia. La medida, de 2007, por iniciativa del gobierno de $\mathrm{CiU}$, fue tachada por el socialista Ballesteros, desde la oposición, como populista y «más efectista que efectiva», pudiendo rozar la ilegalidad. Dos años más tarde, una vez entraron los socialistas en el gobierno, se cambia de estrategia y se cierran filas junto con los vecinos de la asociación, ampliando el proyecto con la instalación de tres cámaras con carácter disuasorio, pero con la intención de colocar más de veinte en 2014 con una partida de 200.000 euros.

Pero un suceso otra vez relacionado con el puerto y el ocio afectaría notablemente al barrio, que volvía a acumular referencias negativas por encima de las protestas vecinales: en la primavera de 2010, dos años después del último conflicto sonado, un grupo de jóvenes fue detenido en la plaça dels Carros tras una pelea en el puerto. Se trataba, según la prensa del día siguiente, de un grupo de Latin Kings, una banda criminal de origen suramericano que había saltado a la fama poco tiempo antes por incidentes violentos en Madrid y Barcelona.

Aunque no se demostrase que eran vecinos y el conflicto fue en el Port Esportiu, muchos sectores vecinales señalan a la sobrerrepresentada comunidad latina del barrio como autora de los conflictos y el incivismo nocturno.

Pues desde el año 2010 bajaron, porque aquí se pagaban alquileres altos, 600700 euros, y ahora vas y por 350 los tienes. Entonces, lo que decimos, itoda esta gente dónde se instala? No en los barrios marginales sino en los sitios más baratos, más económicos. Entonces por eso tenemos bastante gente de esta, que vuelvo a lo mismo, los que vinieron a trabajar y no tienen trabajo se han ido. Entonces, ¿qué nos queda aquí?, la gente que viene a delinquir (RP, vecino $y$ asociado).

También llama la atención al respecto que, aun cuando el modelo de negocio nocturno asentado en el barrio está más bien orientado a consumidores locales y universitarios, los discursos sigan señalando al sector extranjero como el causante de los problemas, incluso en el entorno de esos bares que escasamente frecuentan.

Además, el incidente se sumaba a un conflicto que meses antes se había producido en el puerto, cuando un grupo de inmigrantes denunció la agresión por parte de un portero y el veto a la entrada por la condición de extranjeros. 
El barrio volvería a marcarse en este sentido en 2014, cuando se desarticuló otra banda latina a nivel catalán, los Trinitarios, que contaban con algún miembro alojado en el barrio, aunque las zonas principales de actuación eran Salou-Cambrils, Villafranca y Barcelona. Aunque los detenidos, como afirman algunos vecinos propietarios, aterrizaron en el barrio hacía poco como podían haber caído en otro, las detenciones sirvieron para reforzar el estigma de la latinidad en el barrio, eclipsando las múltiples redadas e incidentes protagonizados por vecinos autóctonos.

\section{El barrio concebido: inmigración, civismo y coaliciones para el futuro}

Un político de la oposición definió el barrio en una de las reuniones con la directiva de la asociación de vecinos como «la zona de la ciudad con mejor posición para el futuro». Un proyecto de renovación de la fachada marítima firmado por el conocido arquitecto Ricardo Bofill en 2006, ligado a una campaña electoral que se preveía negativa para el partido en el gobierno, es el mejor ejemplo. El entonces alcalde, Nadal (CiU), llegó a hablar de la creación de una «milla de oro» para el negocio inmobiliario, que consolidaría la renovación del barrio, elitizándolo de una vez por todas. Resultó un proyecto fantasma por la falta de garantías y dicha condición aumentó el descrédito del político, que perdió las elecciones tras más de veinte años en el poder.

Desde que empezó su repoblación a finales de los años noventa, el barrio es una pieza a ganar en la política y el urbanismo local. El emplazamiento estratégico implica para los políticos la necesidad de contar con el respaldo de los vecinos (al menos de los propietarios) para proyectos futuros. Buscar una concepción común es un trabajo necesario para poder realizar movimientos. Esto ha llevado a que los grupos políticos principales (que durante esta etnografía, en plena campaña electoral, son el PSC desde el gobierno y el PP como principal voz de la oposición) busquen un equilibrio entre los votos, su identidad política, el abanico de vecinos y lo que el resto de la ciudad comprende que debe ser el futuro de esta pieza urbana.

El resultado ha sido la tendencia a formar coaliciones entre agentes sociales, que no son pocos en este caso. Pero este amplio entramado de agentes no está reflejado en los espacios de relación y participación del barrio, donde se da una 
semimonopolización por parte de los partidos políticos y las asociaciones de vecinos y comerciantes. Además, la atracción de instituciones y actividades que hemos explicado con base en la morfología de los locales ha llevado a que el apego de muchas instituciones por el barrio sea reducido y meramente funcional, un hecho que vale para deslegitimar a sectores completos para la participación por parte de otros con identificación consciente con el mismo. Un ejemplo es la mezquita, que no es invitada como tal a actividades del barrio pese al alto número de usuarios.

Así, las administraciones han tenido que equilibrar la condición de vecinos de muchos inmigrantes con el filón de votos que se puede derivar de hacer frentes dentro de las partes, es decir: en un país con poca tradición en la recepción de inmigrantes transnacionales y gestión de una alteridad tan diferenciada, donde los miedos abundan, como hemos visto en las narraciones de algunos vecinos, el discurso islamófobo o el de la incompatibilidad de las culturas arrastra simpatizantes. Un informe de 2010 da muestra de la existencia de un repunte de la islamofobia entre la población de Tarragona (por el instituto CERES, centro de estudios vinculado al sindicato CC. OO.), un hecho que no asume e interviene la administración local pese a la advertencia de que «los números demuestran que la molestia es mayor en los círculos de convivencia cada vez más cercanos» (El País, 27/07/2010). Y es en esos círculos cercanos, en la vida cotidiana y en la interacción, donde puede darse el mestizaje, contactos que pueden resultar «crecientemente conflictivos a medida que la dinámica migratoria y multicultural no está acompañada de suficientes políticas de inserción social y económica, ni de políticas de soporte o de dignificación de las expresiones culturales subalternas» (Pujadas, 2004: 201).

Sin embargo, la globalización ha hecho que determinadas gestiones de la transnacionalidad puedan convertirse en un producto de marketing, pues el mapa multicultural se asocia a un alto nivel de conexión transnacional y adaptación a la contemporaneidad. Así lo anuncia el Ayuntamiento en la web de los Juegos del Mediterráneo 2017, máximo escaparate del momento:

Tarragona es moderna y cosmopolita, y en ella conviven sin problemas gentes de origen muy diverso. Preparados para el mundo global del siglo xxi, sus habitantes ven con ilusión la oportunidad de escribir un nuevo capítulo de su 
historia con la organización de unos Juegos Mediterráneos (<http://www. tarragona2017.org/multiculturalidad.php $>$ ).

En este párrafo se elude el titubeo respecto a la expulsión de las actividades de los inmigrantes a los polígonos industriales, la periferización de la pobreza, las restricciones propuestas por el alcalde socialista a las agrupaciones familiares, las denuncias a la policía por trato discriminatorio a inmigrantes (el último incidente fue en la estación de tren tras un bulo de atentado), ${ }^{1}$ la prohibición del velo integral por motivos de seguridad e integridad moral respecto a la mujer, el artefacto incendiario contra la mezquita de Entrevías o la próxima apertura de la primera sede de la extrema derecha (el Movimiento Social Republicano) en el barrio de Bonavista.

Según los resultados electorales, la vecindad siempre ha tenido una mayor simpatía por los socialistas, pero en los últimos años, ante la trayectoria que antes describíamos respecto a la inmigración y la deriva del ocio nocturno, los sectores más conservadores no dudan en buscar coaliciones estratégicas que tambaleen el reparto de poder. El contacto del grupo socialista con el barrio es frecuente y viene de mucho tiempo atrás, según algunos informantes. De hecho, anualmente el alcalde es invitado por la asociación para hacer una ponencia-repaso en la sede de la misma, una cita donde los vecinos pueden presionar y preguntar. Pero el caldo de cultivo del conflicto social derivado de los temores respecto a los nuevos vecinos ha abierto la posibilidad de conformar un nuevo frente político de corte más conservador. El papel de las instituciones de izquierdas, sindicatos o asociaciones, que en principio debían jugar a favor de una articulación social integradora, no es destacado y apenas tiene visibilidad aquí a diferencia de las asociaciones de propietarios, vecinos o comerciantes. Los grupos de izquierda, al contrario, revisten rasgos xenófobos con la exaltación de la ciudadanía cívica y la consecuente condena de la figura del incívico. Los términos se han potenciado desde que se cuenta con la Ordenanza Municipal de Civismo y Convivencia (aprobada en 2006) que hoy se revisa con el debate

\footnotetext{
1 «Rosa María López, de 57 anys i tarragonina, denuncia un tracte discriminatori i racista "cap al meu fill negre Elián de 15 anys" mitjançant un escrit acompanyat d'una foto familiar publicada a les xarxes socials i compartit per milers de persones en pocs dies i nombrosos comentaris. Es tracta d'una situació donada a l'Estació de Trens de Tarragona, al Barri del Port, durant un dispositiu policial fa un parell de caps de setmana quan també es va desplegar un al Parc Central amb identificació de joves musulmans. El fill adoptat d'aquesta familia resident a Cambrils, va quedar retingut algunes hores, en el seu cas a l'Estació Renfe» (blog Barri del Port).
} 
de si reducir las penas, que es lo que defiende el gobierno local, o aumentar las sanciones, por parte del Partido Popular, que es la petición más que anunciada en el barrio para la formación de coaliciones.

La cuestión de la inmigración será entonces instrumentalizada, poniéndola en relación con la seguridad y el civismo protagonistas en los discursos de los vecinos propietarios y de sectores políticos, como veremos a continuación.

[...] la frecuencia de toda esta gente, de peruanos, chilenos y todo esto, son personas que en principio la mayoría viene a trabajar, pero ¿quién frecuenta por la noche estos bares? [...] Mafia. La persona que va circulando por la calle a la 1 , a las 2 de la madrugada y te lo ves venir de cara, pues ya te da mala sensación (RP, vecino y asociado).

El principio para la formación de una coalición saltó a la vista de los conservadores en 2012, cuando la comunidad islámica Ar-risala quiso transformar su local social de la calle Cartagena, comprado en 2007. El emplazamiento del centro de culto responde a varias cuestiones: los barrios portuarios de Tarragona tienen el mayor porcentaje de inmigración del núcleo urbano, el carácter semiindustrial del barrio hace que este disponga de muchos locales grandes a la vez que la degradación de las edificaciones no los hace especialmente caros. Eso ha hecho que el barri del Port sea, además de un espacio con sobrerrepresentación de inmigrantes, la zona de la ciudad con más diversidad religiosa y con más templos de culto, un hecho que responde a dar servicios a los propios nuevos vecinos y a la oferta de inmuebles. Por eso, además del local social musulmán, el barrio cuenta con una iglesia evangélica china, un templo de testigos de Jehová y la iglesia cristiana pentecostal de Moriah, así como el templo cristiano de Sant Joan. Este hecho, que podría convertirse en un referente o una oportunidad para la interculturalidad, es leído por la vecindad como una manifestación de degradación y de pérdida de atracción de inversores.

El local de Ar-risala funcionaba como punto de encuentro de musulmanes de muy diversa procedencia. Marroquíes, pakistaníes o senegaleses lo frecuentan para leer el Corán, aprender árabe, celebrar nacimientos u otras citas y, según explican los usuarios, establecer redes de solidaridad y ayuda mutua dentro de un sector especialmente castigado por el paro. La petición de regularización y adaptación ponía de nuevo al barrio en el ojo del huracán con un tema delicado por la errónea asociación directa de islam y terrorismo (hay que observar 
que la petición se hace solo dos años después del mayor atentado terrorista de España a manos de Al Qaeda) y de inmigración con delincuencia. La creciente islamofobia, presente en los discursos de una buena parte de los vecinos propietarios, hacía que el barrio ganase de cara al resto de la ciudad significaciones negativas que sumar a la larga trayectoria de incidentes derivados del ocio nocturno y del alto índice de pobreza.

Ese discurso se retroalimenta con los acercamientos del grupo conservador con la cara visible de Alejandro Fernández a medida que han existido movimientos sobre el proceso de regularización de la mezquita (aunque aprovecha otras ocasiones especialmente delicadas respecto al islam como los atentados de Charlie Hebdo en París y un incidente con jóvenes de origen extranjero en el Eroski con la supuesta intención de cometer un hurto, hecho ante el que se decidió a escribir un pasquín rechazando la islamización que supone que implicaría tener la mezquita en la ciudad), que van sumando simpatizantes que se alinean en su concepción del barrio y de la ciudad, que fundamentalmente pretende la elitización y la consecuente expulsión de gente con bajas rentas a la periferia.

En este caso, al contrario de lo que sucedió con el caso de las bandas latinas del Port Esportiu, los informantes que se oponen al emplazamiento de la mezquita no cuentan con una justificación concreta para el rechazo por encima del miedo:

Hay que tener en cuenta que las señoras se asustan cuando ven a tantos moros con las chilabas, todos juntos, es la primera generación de inmigrantes y las mujeres no están acostumbradas, no es como en Francia (RP, vecino y asociado).

También sucede con la atracción y armonía del paisaje respecto a la identidad mayoritaria:

[... ] esto parece el Magreb, a ver quién va a querer comprarse aquí un piso (RP, vecino y asociado).

Estos planteamientos se extraen, aunque con menos claridad y un mayor grado de eufemismos, en el análisis de dicho político, una comunicación que presentó cuando la asociación de vecinos lo invitó a su semana cultural. En esta, como veremos a continuación, se pueden reconocer varias tendencias. Se 
dan un diagnóstico que enfatiza la degradación y necesidad de renovación de una pieza bien posicionada y una acusación a la inmigración como causante de la degradación:

[...] hauria de ser una zona privilegiada al costat del Port [...] la plaça dels Carros no hi ha manera que es revitalitzi i ni la iniciativa privada té interès en invertir en aquella zona que se suposa és privilegiada [... ] al carrer Apodaca hi ha 29 locals abandonats, un 60\% en el cas del carrer Reial, i en general al barri en els darrers cinc anys tan sols prosperen, amb tots els respectes, els kebabs, els locutoris... [Para el conservador, sirven de base] d'altres operacions i activitats il.legals. ${ }^{2}$ [Propone que se haga un análisis] de la situación del salafismo radical en Tarragona como prevención. De momento no tenemos este problema, pero tenemos que estar alerta para que no nos pase como otras poblaciones catalanas. [Pide que se vigile] la estricta igualdad entre hombres y mujeres. [...] cal mà dura i tolerància zero. (Alejandro Fernández, alcaldable del PP en la semana cultural de la asociación de vecinos)

Además de relacionar inmigración con delincuencia, se da una asociación de la inmigración con la insalubridad y se manifiesta la voluntad de emplazar en la periferia (sobre todo en polígonos industriales) a las minorías religiosas (imagen 43). Propone al respecto una regularización de los tipos de negocios para que no puedan concentrarse los vinculados a la inmigración en una misma zona "per evitar que el barri es converteixi en un gueto". De todas las propuestas no hay ninguna en referencia a escasez de viviendas sociales y su ubicación en la periferia ni al paro y la marginalidad.

Las propuestas tienden a criminalizar y profundizar el estigma de los inmigrantes del barrio, especialmente del sector musulmán, que se dibuja como un competidor desleal respecto al comercio tradicional y la vecindad familiar. Así lo expone en la prensa:

Corresponde a los Ayuntamientos decidir el modelo comercial por el que apuestan. Por ejemplo, son muchos los ayuntamientos que prohíben grandes superficies en determinadas zonas, o bien que regulan la tipología de comer-

\footnotetext{
2 Hemos de apuntar aquí que esta parte del discurso sobre las supuestas actividades encubiertas de los locutorios, aun con otros muchos prejuicios presentes aunque focalizados en otros temas, no estaba presente en los miembros de la asociación entrevistados hasta después de la intervención de Alejandro Fernández. Pocas semanas después, en una jornada de contacto con un nuevo alcaldable, se repitieron frases textuales del candidato popular.
} 
cios que pueden ubicarse en sus cascos antiguos. Por lo tanto, es perfectamente legítimo que una opción política quiera limitar la proliferación de kebabs, locutorios o bazares y proteger al comercio tradicional de Tarragona de la competencia desleal que estos practican en muchas ocasiones .(Alejandro Fernández, carta a Diario de Tarragona, 22/01/15)

Aunque los negocios tradicionales empezasen a cerrar antes de la llegada masiva de inmigrantes y uno de los motivos evidentes es la implantación de las grandes superficies comerciales, el discurso de los conservadores señala como causante al pequeño comercio de los nuevos vecinos. Propone:

Los mismos derechos y obligaciones para la gente inmigrante y para la gente nativa. [...] las mismas condiciones legales en términos de horarios comerciales y salubridad para los comercios regentados por inmigrantes [... ]. (Alejandro Fernández en la semana cultural de la asociación de vecinos)

Esa parte del discurso en la que da a entender que hay una pasividad a la hora de aplicar las leyes que favorece a los negocios de los nuevos vecinos transnacionales le sirve para acusar al actual gobierno local de cómplice y, por lo tanto, jugar a hacer frentes colocando al alcalde contra comerciantes y vecinos locales.

Por todas esas razones, Alejandro Fernández afirma que «Tarragona no necesita abrir de nuevo este debate, ni más mezquitas en la ciudad, por eso lo mejor sería mantener durante más tiempo la actual suspensión en la tramitación de nuevas licencias».

Uno de los miembros implicados del centro lo defiende explicando:

No somos terroristas. [...] Lo bueno sería tener una mezquita y que todos en la ciudad la pudiesen visitar, no solo nosotros [...] pero la gente no quiere [...] la gente no conoce nada, hay miedo porque no hay integración, no saben de los musulmanes. (BE, senegalés)

El mismo informante se muestra sensible a los miedos de la sociedad occidental respecto al islam por desconocimiento y acepta que la situación implique un tratamiento distinto del poder público respecto a ellos en comparación con los otros centros de culto. Una condición por la que de momento prosigue la mezquita en el barrio es un acuerdo de colaboración contra el salafismo con la aceptación de arduos controles. 
Además, se tiene la sensación, no sin falta de razón, de que las ordenanzas se modifican a voluntad de la concepción del urbanismo de la ciudad y no de pautas técnicas, de modo que la mezquita nunca deja de peligrar. Una posible coalición del sector islámico del barrio por encima de los mismos usuarios es compleja por la escasa interrelación con el resto de la vecindad según algunos de ellos señalan. Además, sorprende la poca información de muchos usuarios de la mezquita respecto a los movimientos gentrificadores e islamófobos del sector más conservador de la ciudad.

La concepción de la ciudad de los conservadores implica una enorme segregación que no deja de estar acorde con las tendencias mayoritarias en Cataluña (también en ayuntamientos gobernados por partidos de izquierdas), donde muchos ayuntamientos han expulsado los centros de culto a los polígonos industriales a través de ordenanzas municipales que aluden a cuestiones como la insonorización, la seguridad o la movilidad para justificar lo que algunos sectores del barrio no dudan en ocultar:

¿Quién va a querer invertir aquí con todos los moros? El que quiera montar un hotel lo monta antes en otro barrio, [...] lo mismo con las tiendas de calidad $[\ldots]$ no van a abrir una cadena de nivel con un locutorio al lado [...]. Los inversores buscan seguridad. (RP, vecino asociado)

El rédito electoral que la inmigración ofrece en tiempos delicados para la convivencia ${ }^{3}$ hace que el grupo del gobierno local no tome una postura clara, de modo que lanzan titulares que hablan de la necesidad de regularizar la cuestión de los centros de culto a la vez que piden paciencia a la vecindad para ganar margen de maniobra.

Este frente formado en torno a la cuestión de la mezquita puede pasar factura a un bastión del grupo en el gobierno, el PSC. En este sentido, se interpretan dos movimientos a escasos meses de unas elecciones municipales: en primer lugar, la aprobación de unos presupuestos destinados a algunas mejoras del espacio público de la Part Baixa y el barri del Port (en concreto, en la plaza dels Infants), y en segundo lugar, una vieja reclamación como la renovación de la estación de trenes, que el barrio la siente como propia. El alcalde socialista,

3 Hay que tener en cuenta que, en paralelo a estos hechos, la mezquita principal fue atacada con un objeto incendiario en 2014 a la vez que se abría en el barrio de Bonavista la primera sede social de la extrema derecha, en concreto, del Movimiento Social Revolucionario, que se dedica entre otras cuestiones a asistir con ropa y comida exclusivamente a familias españolas con necesidades. 
Ballesteros, eleva el tono de sus reclamaciones ante el Gobierno y pide personalmente al barrio que secunden la campaña de presión con la recogida de firmas y con la disponibilidad para la movilización en caso de negativa. Las negociaciones han sido favorables a las peticiones de la alcaldía y a la voluntad del barrio, lo que ha llevado a cierta sensación de éxito y a reforzar la vinculación con el socialismo. Los efectos de los ajetreados movimientos de los políticos respecto al barrio podrán contrastarse en unos meses, con los resultados de las elecciones municipales.

\section{Algunas notas sobre la participación y la represen- tación a la hora de concebir y transformar el barrio}

El discurso del candidato conservador a la alcaldía no es la única manifestación que se ha dado en el barrio en este sentido ni debemos pensar que todas esas construcciones vienen unidireccionalmente de dicho sector político, pues, como hemos visto, incluso en un barrio de amplia tradición socialdemócrata, se multiplican los discursos xenófobos. Una muestra de esta dinámica, que a nosotros nos interesa en relación a las formas de concebir y transformar la ciudad, pude presenciarla en los acercamientos de los grupos políticos a las asociaciones vecinales en tiempos de precampaña municipal. En las reuniones, se convoca a las directivas de las asociaciones de vecinos para tratar de recopilar las necesidades de los vecinos, y el grupo político, que se presenta en el barrio con una pequeña comisión, expone algunas propuestas y recopila información sobre las necesidades tratando de crear así un canal de comunicación de cara a la vida en el poder o en la oposición. Aquí podemos detenernos para observar varias cuestiones relevantes en cuanto a la participación ciudadana respecto al urbanismo, las políticas locales y la interlocución.

En primer lugar debemos observar que el movimiento vecinal, aun contando con un alto número de asociados en el caso concreto del barrio (donde se superan los 500 asociados), no refleja la diversidad real del barrio. Ni tan siquiera representa al sector de los propietarios, ya que los vecinos de las nuevas viviendas, con la excepción de casos de vecinos originarios del barrio que han vivido un proceso de retorno tras abandonarlo por mala habitabilidad, están inscritos en comunidades de propietarios según las promociones y no en la aso- 
ciación primera y original. Por tanto, esta institución representa a los propietarios de un periodo concreto (mitad de los ochenta) que vieron la necesidad de asociarse. De ese periodo de lucha vecinal, como en muchos otros barrios, derivó la revitalización cultural. Esto ha hecho que, pasado el fenómeno del asociacionismo vecinal, la gente joven se haya sentido atraída por otras formas de hacer barrio más ligada a las instituciones folklóricas y fiesteras (como la Cucafera, los Gigantes, etc.), y que la asociación quede como un espacio de socialización de vecinos con una media de edad muy alta. Un hecho significativo sobre la función de la institución es que fundamentalmente cumpla con las actividades típicas de un hogar de jubilados (excursiones, chocolatada, castañada, bingo, etc.), como ellos mismos explican a la hora de reclamar un equipamiento de estas características. Las actividades reivindicativas, aun siendo a priori el leitmotiv del asociacionismo, ocupan un papel secundario y cuentan con menos participación por parte de los asociados.

Vemos, por tanto, que dicha institución, aun portando una denominación tan significativa como Asociació de Veïns del Barri del Port, y habiendo sido durante un largo tiempo altamente representativa, hoy no engloba a los vecinos de las nuevas edificaciones, no recoge a los vecinos en régimen de alquiler (que son muchos en esta zona de viviendas antiguas) y no refleja al sector de los usuarios o comerciantes. No obstante, desde la asociación se mantiene que se trabaja por el interés general de los vecinos del barrio, para que "cuenten con buenos servicios, que el barrio esté limpio y seguro, para que siempre vaya mejorando como sitio para vivir" (RP, vecino asociado). Sin embargo, como veremos, no es para que todos prosperen.

Pero no se limita a este hecho la escasa representación, sino que llega más allá, como veremos si observamos el tratamiento de la alteridad. Debemos aclarar aquí que cuando hablamos de interlocución para la participación hablamos de dos partes reunidas, de modo que debemos observar la concepción de los vecinos asociados y la de los grupos políticos, pues de ambas construcciones derivarán discursos generales que pueden o no asentarse en el imaginario urbano con distintos resultados. $\mathrm{Al}$ respecto apuntaremos que, aun sin la posibilidad de citar por el impedimento de grabar los encuentros y por preservar el anonimato en pro de no dañar al barrio y sus instituciones, algunas anotaciones en el cuaderno de campo son significativas en cuanto a la representación e in- 
terlocución y nos permitirán realizar un esbozo al respecto. Hemos de aclarar que cuando se usa el concepto «los vecinos» hacemos referencia a una mayoría representada ese día y no a personas concretas, aunque las opiniones de muchos asociados puedan tener muchos más matices e incluso diferir.

Primera nota: "El problema con la inmigración (así presenta el tema, como problema; el tema lo empiezan ellos)". Vemos aquí que la cuestión de la alta presencia de inmigrantes en el barrio es sacada por el grupo político como ítem y que además se hace en términos de problema.

Segunda nota: "La caja de Pandora de los vecinos: expulsión, cortar el grifo de las ayudas, competencia desleal, vagancia, «purria», «la mierda baja»". Llama la atención la poca delicadeza con la que, aun con un observador ajeno como yo o los mismos políticos, hablan sobre un sector que supera el $24 \%$ del barrio.

Tercera nota: Nadie (grupo político) pone límite. El líder no se moja y los subalternos refuerzan comentarios. "Yo no me fío de ninguno".

Derivan de esta etnografía varias preguntas en relación a las formas de concebir y transformar la ciudad. Respecto al sector político, cabe preguntarse cómo puede poseerse la entrada en un puesto de responsabilidad política local ignorando y estigmatizando a una parte destacada del tejido social de la ciudad y el barrio, si no debe ser el sector político el que justamente canalice los conflictos y evite la proliferación de ideologías xenófobas para garantizar la mejor convivencia posible incluso aceptando distancias culturales, si no deberían existir contactos con otras instituciones del barrio a la hora de recopilar carencias y propuestas. $Y$ en relación a los vecinos es necesario plantearse si no deberían darse, con el fin de ser legítimos representantes del barrio, acercamientos respecto a las instituciones periféricas, nuevos vecinos y comercios. Además, especialmente desde las posiciones capaces de crear contenido, por ejemplo la academia, es preciso resaltar lo injusto de recriminar a los nuevos vecinos $y$ comerciantes la decadencia del comercio tradicional sin mencionar la instalación de otros factores aún más condicionantes como las grandes superficies o la torpeza a la hora de trazar estrategias para su revitalización barrial. Y respecto a los nuevos vecinos afirmamos que es necesario aumentar la porosidad de las instituciones y/o constituir otras nuevas con el objetivo de ser espacios de convivencia. Es primordial para permanecer (véase el caso de la mezquita) trabajar, además de en relación con los políticos, a nivel de vecinos. 
Concluimos afirmando que estamos ante una situación de falta de canales y/o sustitución más o menos consciente de roles de representación de instituciones y que contamos con instituciones más dirigidas a la autodefensa de intereses que a la confluencia de los mismos. 


\section{Bibliografía}

Achebak, H. y González, J. A. (2015). “Agrupació i segregació espacial de la població de nacionalitat marroquina a Tarragona, 2004-2012". Documents d’Anàlisi Geogràfica, 61(1), 23-47.

Alonso, M. (2011). "Socioacústica y etnografía urbana. Reflexiones en torno al caso de la Part Alta de Tarragona". Arxiu d'Etnografia de Catalunya, (11), 51-76.

Cuberos Gallardo, F. J•y Martín Díaz, E. (2012).“Conflictos identitarios en los espacios públicos: las ligas deportivas latinas en la ciudad de Sevilla". Revista de Ciencias Sociales (Cl), (28).

De Ortueta Hilberath, E. (2006). Tarragona: el camí cap a la modernitat: urbanisme $i$ arquitectura. Lunwerg.

Delgado, M. (2007a). "Ciudades sin ciudad. La tematización «cultural» de los centros urbanos". En: Antropología y Turismo. Claves culturales y disciplinares, 91-109.

Delgado, M. (2007b). La ciudad mentirosa: fraude y miseria del modelo Barcelona (Vol. 257). Madrid: Los libros de la Catarata.

Escoda Múrria, C. y Baiges, L. (2005). El naixement dels barris del port. Centre d'Estudis Marítims i d'Activitats del Port de Tarragona.

Fernández Durán, R. (2006). El tsunami urbanizador español y mundial: sobre sus causas y repercusiones devastadoras, $y$ la necesidad de prepararse para el previsible estallido de la burbuja inmobiliaria. Barcelona: Virus Editorial.

Franquesa, J. (2013). Urbanismo neoliberal, negocio inmobiliario y vida vecinal: el caso de Palma. Icaria.

Franquesa, J. (2017)."El compromiso antropológico a partir del segundo milagro español: desmitificar lo real y rescatar lo posible". En: Antropologías en transformación: sentidos, compromisos y utopias (pp. 39-64). Institució Alfons el Magnànim.

González, M. (2011)."El Serrallo de Tarragona: de barrio marinero a enclave temático para turistas y visitantes". Arxiu d'Etnografia de Catalunya, (11), $115-130$.

Harvey, D. (2013). Ciudades rebeldes: del derecho de la ciudad a la revolución urbana. Ediciones Akal. 
Lefebvre, H. y Lorea, I. M. (2013). La producción del espacio. Madrid: Capitán Swing.

Lynch, K. (1985). La imagen de la ciudad. Barcelona: Gustavo Gili. (Original, 1960).

Moix, L. (2010). Arquitectura milagrosa. Hazañas de los arquitectos estrella en la España de Guggenheim. Barcelona: Anagrama.

Nogué, J. (2007). La construcción social del paisaje. Madrid: Biblioteca Nueva.

Pujadas, J. J. (2004). “Cultura, imágenes urbanas y espectáculo. A propósito del ecumenismo multicultural de la Barcelona del Fórum 2004”. Revista Sociedad y Economía, (6).

Sмith, N. (2009). “¿Ciudades después del neoliberalismo?”. En: VV. AA., Después del neoliberalismo: ciudades y caos sistémico. Barcelona: CCCB. 